\title{
Design of mass notification systems
}

\author{
M. Reiss ${ }^{1} \& \mathrm{~F} . \mathrm{Li}^{2}$ \\ ${ }^{1}$ Rolf Jensen \& Associates, Inc., USA \\ ${ }^{2}$ Rolf Jensen \& Associates, Inc., China
}

\begin{abstract}
Mass notification systems (MNSs) are a relatively new concept as a result of the problems that occurred in maintaining communications and directing occupants to safety on September 11, 2001. The design of a MNS combines both a communications infrastructure and an emergency management strategy that will deliver real-time information and instructions to people in a single building or on an entire campus. This paper addresses the eight steps in the design of a successful MNS. They are the analysis of the threat, how the facility operates on a daily basis, development of a master plan, integration of the personnel alerting subsystems, development of an emergency action plan, implementation, staff training and periodic review.
\end{abstract}

Keywords: mass notification, emergency communication, personnel alerting, occupant safety.

\section{Introduction}

A gunman goes on a killing rampage in a crowded hotel. A suspicious package is found in the mailroom of a large corporation. A devastating hurricane causes massive damage to a large region. A fire strikes a college dormitory. Terrorists plant a dirty bomb in a densely populated area.

These isolated events read like the front page of a newspaper on a bad day. But they also reflect the realities of living, learning, working and recreating in a world facing an unprecedented level of security threats. To combat these incidents, owners and managers of buildings ranging from high-rises and hospitals to educational campuses and large occupancy venues are ramping up their efforts to protect the people who use their facilities on a daily basis. 
An important component of any building safety program is an effective mass notification system (MNS). The MNS combines a communications infrastructure and an emergency management strategy designed to deliver real-time information and instructions to people in a single building, on an entire campus or in remote locations globally.

Mass notification is a relatively new concept, born out of a collective inability to maintain communications and direct building occupants to safety during the events of September 11, 2001 at the World Trade Center in New York City. The United States Department of Defense (DoD) led the way by publishing a Unified Facilities Criteria (UFC) which called for antiterrorism features to be included in all force protection plans for DoD facilities worldwide. Other events around the world since September 11, 2001 have made this a global issue in both the public and private sectors. These systems must be capable of providing real-time information to all building occupants or personnel in the immediate vicinity during emergency situations.

\section{MNS basics: alert the personnel and mange the emergency}

Whether the threat to your facility is an approaching storm or a man-made intrusion, your MNS must be capable of personnel alerting, the act of notifying your occupants what is happening, where to go, and what actions to take to maximize their safety and when the event is over and it's safe to resume normal operations.

Mass notifications systems protecting facilities in the private sector typically utilize existing high-speed voice and data networks to deliver pre-recorded or live paging, text and graphical messages to wired and wireless communication devices. This personnel alerting capability can involve the use of voice-enabled fire alarm systems; indoor/outdoor speakers; visible signal systems; telephone systems; cell phones and pagers, radios; digital video/graphic signage; wired/wireless computers and a host of personal communication devices.

A major goal of personnel alerting is to create interoperability between various disparate communication systems. This effort recognizes the reality that people who need to receive the mass notification message may be mobile and, therefore, not always in hearing distance of a loudspeaker or vocal alarm. So other forms of communication - text and graphical messaging - must be included in the MNS design to insure a successful link between sender and receiver in an emergency situation.

Equally important, and often overlooked, is the necessity to plan for potential events and execute the proper response to the emergency. The purpose of emergency action plans is to establish appropriate procedures and actions personnel should take during a variety of different events. By doing your planning upfront in a calm, non-emergency environment, your actions, reactions and responses to events can be developed to provide the maximum safety to your occupants. 


\section{The steps in the design of a successful MNS}

As the adage goes, "plan your work and work your plan." The more preparation you put into your MNS planning effort, the better your efficiency in protecting the staff and occupants in your facility. An independent MNS consultant, experienced in life safety, security, communications and emergency response, but having no ties with communication system manufacturers, can play an important role in helping you design and implement an effective MNS.

Step 1 - Analyze the threats to your facility and its occupants. This should be a comprehensive assessment of a single facility, a campus-type complex or even a global organization. The purpose is to identify strengths, weaknesses, vulnerabilities and deficiencies. The analysis helps to determine what could happen, when, where and under what circumstances, as well as how prepared your facility is to respond to an emergency event. The result of the threat assessment is a report that provides a framework of information upon which a workable MNS strategy can be built.

Step 2 - Gather input on how your facility operates on a daily basis. This step involves a thorough investigation of how your facility operates under normal conditions. The security of your facility should be evaluated from an architectural, technical and procedural standpoint. What communication systems are in place? Are they up to current standards or do they reflect obsolete technology? How do they interact with one another... or do they interact at all? What type of safety and security staff do you employ? Are they trained? What procedures are in place for emergency response? The answers to all these questions and more provide the framework for the MNS master plan.

Step 3 - Develop an MNS master plan. An enterprise-wide MNS strategy needs to address both the short-term and long-term requirements of your facility. A comprehensive master plan provides an effective approach to building or campus-wide personnel alerting and emergency response in a single, integrated, written document. The objective is to meet immediate mass notification needs while addressing the complexities of interoperability between disparate wired/wireless communication systems. An intelligent master plan also helps to satisfy longer term emergency preparedness objectives in a more organized and cost effective manner.

Step 4: Integration of personnel alerting systems. The communication systems must be carefully designed to ensure reliable performance in any emergency situation first and foremost. The total system also must be seamless to offer a cost effective mass notification capability while integrating many or all of the following subsystems:

- Indoor/Outdoor Speakers

- Voice Evacuation/Fire Alarms

- Telephone, Cell Phones and Pagers 
- Radios and Wireless Devices

- Digital Video/Graphic Signage

- LANs and WANs

- Mass Notification Message Control System

- Digital Voice/Text/Graphic Messaging

Step 5: Develop the emergency action plan. This is a tactical plan of how the organization will react in various emergency scenarios. The emergency response plan defines each potential emergency event and provides a step-by-step response to the event. It integrates the actions of multiple departments or units within a facility such as facilities management, operations, security, human resources and public relations to ensure a rapid, effective and coordinated response to a disaster or emergency event.

Step 6: Create a phased implementation. Implementing the proper MNS solution for your facility requires the same discipline as managing a new construction or retrofit project. A budget needs to be prepared, specifications developed and bids from qualified suppliers obtained and evaluated. Once the contracts are awarded, it becomes a matter of managing the installation process of the integrated system, from contract administration and quality control to final testing and acceptance.

Step 7: Train the staff and conduct drills. Your MNS team needs to be thoroughly familiar with the procedures for your facility's emergency action plan; their roles and responsibilities under each scenario; as well as the operational features of the mass notification systems you are employing. Training should be provided and drills conducted where building occupants are either evacuated to safe areas or ordered to take shelter-in-place, depending on the type of simulated emergency. The results of the drills should be evaluated and used to improve your facility's MNS strategy.

Step 8: Conduct periodic MNS reviews. Most facilities are in a constant state of change. In order to keep your MNS strategy at the highest possible performance level, you need to evaluate your MNS solutions over an extended period of time as new threats emerge, technology advances and your facility continues to evolve. For maximum effectiveness, a process should be set in place that provides reviews and tests on a regularly scheduled basis (i.e. every six months or annually).

\section{Conclusions}

The function of a mass notification system is to provide real-time information and instructions to all building occupants or personnel in the immediate vicinity of a building, campus or geographic area during an emergency situation or event. To reduce the risk of mass casualties, the MNS must be carefully designed to provide a timely means to notify personnel of threats and to instruct them on 
what they should do in response. Thanks to quantum leaps in communication technology, we have the means to deliver accurate messages to people via an impressive range of devices... anywhere in the world. Successful MNS systems have been placed in service using the above 8 steps in the United States and China. Whether we're protecting spectators in a huge stadium or thousands of students on a college campus, the MNS objective is well worth the price. 